\title{
Research on the Replacement of Coal by Electricity in East China
}

\author{
D.X. Jia, B.G. Shan \\ Economy, Energy Supply and Demand Research Institute, State Grid Energy Research Institute, PRC
}

\begin{abstract}
Large quantity of coal has been burned directly in East China for a long time, which is one of the main reasons for environmental pollution. Taking the minimal total cost per year as objective, and the national reduction of coal burned directly and the manufacturing capability of main coal replacement technology as constraints, with China's total quantity control on coal consumption and action plan of energy conservation and emission reduction, an optimization model on replacement of coal by electricity in large scope is proposed. In future, market prospect of replacement of coal by electricity is booming, under the support of national policy and reasonable multi-win of every participator. An example from East China shows the above model's feasibility and efficiency. The research can be referred by long term planning of national replacement of coal.
\end{abstract}

Keywords-replacement of coal by electricity; market prospect; optimization model; emission reduction

\section{INTRODUCTION}

\section{A. Background}

In recent years, there have been many times of serious haze in East and Central China, which influenced the safety of transportation, property, health, and other sections of social producing and living. Research shows that, emission from coal burning was one of the main reasons for environmental pollution. In China, coal consumption took up $70 \%$ of primary energy consumption. There was about 8 tons of coal, nearly $15 \%$ of primary energy consumption, which was burned by boiler, kiln of middle and small capacity, individual cooking and heating in winter in year 2012. The efficiency of coal burned directly was very low, and its pollution was emitted near ground, which influenced environmental quality more seriously. Recently, more and more coal burned directly was reduced by government, and many kinds of action plan of energy conservation and emission reduction were issued. Thus, replacement of coal by electricity will be very important.

\section{B. Reviews}

Paper 1 surveyed the energy consumption structure of boiler users in Nanjing city by a stratified random survey method, analyzed the economic evaluation of one typical enterprise that will replace the gas with electrical energy, and put forward some proposals for the promotion and application of electric energy[1]. To resolve the problem of tremendous curtailment of wind power in the power grids of Northeast China, North China and Northwest China during heating period in winter, paper 2 proposed that the constraint of forced power output determined by heat be decoupled by installing an electric boiler in the thermoelectric plant[2]. As for electric boiler heating enjoys unparalleled advantages compared with other heating methods, paper 3 expounded the advantages and influences of electric boiler heating and analyzed how it influenced the construction of electric power network and the operation of Heilongjiang Grid[3]. In the light of the illumination characteristics and the specific features that the outdoor temperature in winter in the northern frigid regions is excessively low,paper 4 presented a scheme for heating by using solar energy-soil source heat pumps and the influence of such factors as the primary energy utilization efficiency and the operation cost of different kinds of heating were compared and analysed[4]. Paper 5 introduced main kinds of electric heating, analyzed main kinds of heating in Lanzhou city, compared their economy and put forward some advice on selection of electric heating[5]. In hot summer and cold winter region, for a building in Shanghai city in winter, the ground source heat pump is combined with dry coil to heat the office space, comparing the electric boiler with a heat storage system in the same heating capacity. By anaylzing these two ways of energy consumption, paper 6 proposes that if considering the initial investment, ground source heat pump will save $35.1 \%$ of energy that consumed by the electric boiler with heat storage system[6]. In order to improve the system reliability and the heat source efficiency and reduce initial investment, the design project is proposed by paper 7 to set up peakshaving heat source of regional single heat source heating system. Based on the coal-fired boilers and electric boiler characteristics, geographical features and architectural energy characteristics, the peak-shaving heat source of some single heat source heating system is optimized by annual cost method. The best capacity and start-up temperature matching the peakshaving heat source characteristics have been confirmed[7]. Paper 8 presents an analytical study of the designing method, equipment choosing and application of the accumulative electric hot water boilers used as the heat resource in small medium sized buildings, which has been proved by the example of application of the AC system as the heat resource in a shopping center[8].

Main of the above papers focused on the economy of local replacement of coal by electricity, and lacked in the analysis of market prospect, cost and benefit of the replacement of coal by electricity in large scope.

\section{Main Tasks}

Taking the minimal total cost per year as objective, considering China's total quantity control on coal consumption and action plan of energy conservation and emission reduction, an optimization model on replacement of coal by electricity in large scope is proposed. Based on many surveys, taking a 
province of East China for example, the scale of replacement of coal by electricity is proposed, with its benefit analysis, and some policy suggestion is put forward. The research can be referred by long term planning of national replacement of coal.

\section{MODEL AND SOLVING METHOD}

\section{A. Model}

Considering China's energy balance between supply and demand, total quantity control on coal consumption and action plan of energy conservation and emission reduction, according to different kinds of coal replacement technology and their change laws of technique and economy, using the minimal total cost per year as objective, and national reduction of coal burned directly and producing capability of main kinds of coal replacement technology as constraints, an optimization model on replacement of coal by electricity in large scope is put forward as follows.

$$
\begin{aligned}
& \min c=\sum_{i=1}^{N}\left[c_{i}\left(q_{i}\right) \times q_{i}\right] \\
& \text { s.t. } \quad \mathrm{E}=\sum_{\mathrm{i}=1}^{\mathrm{N}}\left[\mathrm{e}_{\mathrm{i}}\left(\mathrm{q}_{\mathrm{i}}\right) \times \mathrm{q}_{\mathrm{i}}\right] \\
& \mathrm{q}_{\mathrm{i}} \leq \mathrm{Q}_{\mathrm{i}} \\
& \mathrm{c}_{\mathrm{i}}\left(\mathrm{q}_{\mathrm{i}}\right)=\mathrm{a}_{\mathrm{i}}\left(\mathrm{q}_{\mathrm{i}}\right)+\mathrm{f}_{\mathrm{i}} \times \mathrm{p}_{\mathrm{i}}
\end{aligned}
$$

Where, $\mathrm{c}$ is total cost per year of the replacement of coal. $q_{i}$ is the scale of the ith coal replacement technology. $c_{i}\left(q_{i}\right)$ is the unit cost per year of the ith coal replacement technology, which is estimated according to the cost change law of similar technology against its producing capability, and is checked with expert's estimation. $\mathrm{N}$ is the quantity of coal replacement technology choice. Type of fuel includes natural gas, electricity, etc. Type of equipment includes boiler, kiln, etc. E is the scale of coal replacement at target year. $e_{i}\left(q_{i}\right)$ is the quantity of coal replaced by the $\mathrm{i}$ th coal replacement technology at its unit scale, considering its energy utilization efficiency, which is calculated by equivalent heating value method. $Q_{i}$ is the upper limit of producing capability of the ith coal replacement technology at target year, which is estimated according to the producing capability change law of similar technology against social demand and the influence of other kinds of coal replacement technology, and is checked with expert's estimation. $a_{i}\left(q_{i}\right)$ is the annuity of the $i$ th coal replacement technology at its unit scale, excluding its residual value. $f_{i}$ is the annual fuel consumption of the $i$ th coal replacement technology at its unit scale. $p_{i}$ is the fuel price of the ith coal replacement technology.

\section{B. Solving Method}

The above model is solved by adoption of nonlinear optimization function, fmincon(), of commercial math software MATLAB. Data format of input and output is excel table. Main solving steps are as follows.

The initial value of variables is determined by various combination of their maximum value, minimum value and mid-value. The optimization is calculated respectively. If the error among all these outputs is acceptable, the scheme of minimum objective is taken as final output. If the error among all these outputs is unacceptable, the combination methods of initial value of variables are increased. The optimization is calculated respectively again, and the scheme of minimum objective is taken as final output.

\section{SIMULATION TEST}

\section{A. Input Data}

Take a province in East China for example. Its GDP of year 2012 was about RMB 5 thousand billion yuan. Its coal consumption was about 0.39 billion tons, which held $76 \%$ of primary energy consumption. The consumption of coal burned directly and inefficiently was about 0.13 billion tons, which was used for industrial production, hot water supply, and individual heating in winter, etc. The province proposed that, the coal share of primary energy consumption drop to about $60 \%$ in year 2020.

Other main input data is as follows. price of natural gas for civil use is about RMB 2.7 yuan/m3. Residential electricity price is about RMB 0.5469 yuan/kWh. $1-10 \mathrm{kV}$ industrial normal price is about RMB 0.8207 yuan $/ \mathrm{kWh}$, while its valley price is about RMB 0.596 yuan $/ \mathrm{kWh}$. The investment of heat pump is about RMB 300 yuan $/ \mathrm{m} 2$ according to heating area. Normal one-ton-steam electric boiler's investment is about RMB 0.6 million yuan, while that of heat storage electric boiler is about RMB 1.5 million yuan, and that of natural gas boiler is about RMB 0.65 million yuan. Investment of electric kiln with mid capacity is about RMB 50 thousand yuan, while that of natural gas kiln is about RMB 1.5 million yuan. The average annual scale growth rate of every coal replacement technology is less than $100 \%$. When the scale growth rate of one coal replacement technology is more than $100 \%$, its unit investment decreases by $2 \%$, and its energy utilization efficiency increases by $1 \%$.

\section{B. Testing Results}

Considering the production capability weeded out because of inefficiency and that increased by the development of society and economy, according to the above model and the main input data, the quantity of coal to be replaced by electricity will reach to 55 million tons in year 2020, which accounts for $71 \%$ of the decrease of coal to be burned directly. Among the decrease of coal to be burned directly, that to be replaced by electric boiler will be 7 million tons, which can produce 14 thousand tons of steam. That to be replaced by heat pump will be 25 million tons, which can supply heating and refrigerating for 0.18 billion $\mathrm{m}^{2}$ of buildings and hot water for production and living. That to be replaced by mid- low temperature electric kiln will be 14 million tons. That to be replaced by home electric appliance and individual heating will be 9 million tons.

There is much effect of energy conservation and emission reduction resulted from the implement of coal replacement by electricity. By which, the increase of electric power demand will be $34 \mathrm{GW}$ in year 2020. That of electric energy demand will be $89 \mathrm{TWh}$, which increases the market share of electric energy by $14 \%$. It could reduce 550 thousand tons of emission 
of $\mathrm{SO}_{2}, 440$ thousand tons of emission of $\mathrm{NO}_{\mathrm{x}}$, and 12.4 thousand tons of emission of $\mathrm{PM}_{2.5}$. If all increase of electric energy demand is supplied by wind power generation or PV generation, it will increase $45 \mathrm{GW}$ of wind power generation or $64 \mathrm{GW}$ of PV generation, and will reduce 110 million tons of emission of $\mathrm{CO}_{2}$.

\section{Strategy of Generalization}

The generalization of coal replacement by electricity needs much support from national policy, and the situation of multiwin. The coal replacement by electricity should be brought into social commonality management and development planning of city. The electric price should be laid down reasonably, including the electric price policy of peak and valley, to promote the guidance function of electric price to energy consumption. The projects of coal replacement by electricity, including investment on relevant distributed electric power network, should be supported by financial subsidy, reduction of tax and fee, etc.

\section{CONCLUSIONS}

The implement of coal replacement by electricity is very important to improve environmental quality and to promote the development of electrical industry. Considering coal replacement technology choice and its change law of technique and economy, China's total quantity control on coal consumption and action plan of energy conservation and emission reduction, taking the minimal total cost per year as objective, and the national reduction of coal burned directly and the manufacturing capability of main coal replacement technology as constraints, an optimization model on replacement of coal by electricity in large scope is proposed. There is much effect of energy conservation and emission reduction resulted from the implement of coal replacement by electricity, including the promotion of new energy's development, supported by national policy and situation of multi-win. An example from East China shows the model's feasibility and efficiency. The research can be referred by long term planning of national replacement of coal.

\section{BIOGRAPHY}

D.X. Jia (1971-), Male, Ph.D of Power System and its Automation. Dr. Jia is a senior engineer of State Grid Energy Research Institute, Registered Electrical Engineer (Power Generation, Transmission, and Transformation), Registered Consulting Engineer (Investment). Dr. Jia is experienced in research on energy and power economic, including energy base construction and power industry long term development planning, international energy cooperation, power industry planning, power supply expanding planning, trans-region power grid expanding planning and power flow analysis, power production simulation, power system optimized operation, energy-saving generation dispatch, power project technical and economic evaluation, environmental economic research, power market and power project post-evaluation, etc.

B.G. Shan (1971-), Male, MA of Power System and its Automation. Mr. Shan is a senior engineer of State Grid Energy Research Institute, Registered Consulting Engineer
(Investment). Mr. Shan is experienced in research on energy and power economic demand forecast, etc.

\section{REFERENCES}

[1] Wu Ling, Liu Qiuhua, Niu Wenqi, Survey Analysis on Energy Substitution of Boilers in Business [J]. Journal of Industrial Technological Economics, 219(1):pp. 31-36,2012.

[2] LYU Quan, Jiang Hao, Chen Tianyou,et al, Wind Power Accommodation by Combined Heat and Power Plant with Electric Boiler and its National Economic Evaluation[J].Automation of Electric Power System,38(1):pp. 6-12,2014.

[3] Meng Yi, Influence of electric boiler heating on the construction and operation of Heilongjiang Grid [J].Heilongjiang Electric Power,32(2):pp. $149-150,154,2010$.

[4] Liu Yi,Li Bingxi,Fu Zhongbin,et al, Analysis of the Operation Costeffectiveness of a Solar Energy-Soil Source Heat Pump in Frigid Regions [J].Journal of Engineering for Thermal Energy and Power,26(4):pp. 471-474,498-499,2011.

[5] He Xiqing, Wang Zhouxuan, Li Xiaojiang,et al, Analysis of operation effect of heating system such as electric heating water-source heat pump etc [J].Power DSM,14(3):pp. 28-32,2012.

[6] Gao Xiaolin, Weng Wenbing, Jia Jingwu,et al, Energy- saving measuring and analysis with the (ground source heat pump) (GSHP) and the electric boiler for a heating system in a certain office building of shanghai in winter [J].Building Energy Efficiency,40(2):pp. 9-12.

[7] Sun Chunhua,Yan Binghong,Qi Chengying, Electric storing heat as peak-shaving heat source analysis of regional central heating system [J].Journal of Heibei University of Technology,39(6):pp. 76-80.

[8] Wang Kun, Regenerative electric boiler water as a heat source of small buildings w inter [J].Journal of Hebei Polytechnic University( Natural Science Edition), 32(1):pp. 30-33. 